\title{
A DNA sensor based on upconversion nanoparticles and two-dimensional dichalcogenide materials
}

\author{
Konstantina Alexaki $^{1 *}$, Davide Giust ${ }^{1 *}$, Maria-Eleni Kyriazi ${ }^{1}$, Afaf H. El-Sagheer ${ }^{2,3}$, Tom Brown ${ }^{2}$, \\ Otto L. Muskens ${ }^{1,4}$, Antonios G. Kanaras $(\bowtie)^{1,4}$ \\ 1 School of Physics and Astronomy, Faculty of Engineering and Physical Sciences, University of Southampton, Southampton SO17 1BJ, UK \\ 2 Department of Chemistry, University of Oxford, Chemistry Research Laboratory, Oxford OX1 3TA, UK \\ 3 Chemistry Branch, Department of Science and Mathematics, Faculty of Petroleum and Mining Engineering, Suez University, Suez 43721, Egypt \\ 4 Institute for Life Sciences, University of Southampton, Southampton SO17 1BJ, UK
}

(C) The Author(s) 2021. This article is published with open access at link.springer.com and journal.hep.com.cn

\begin{abstract}
We demonstrate the fabrication of a new DNA sensor that is based on the optical interactions occurring between oligonucleotide-coated $\mathrm{NaYF}_{4}: \mathrm{Yb}^{3+} ; \mathrm{Er}^{3+}$ upconversion nanoparticles and the two-dimensional dichalcogenide materials, $\mathrm{MoS}_{2}$ and $\mathrm{WS}_{2}$. Monodisperse upconversion nanoparticles were functionalized with single-stranded DNA endowing the nanoparticles with the ability to interact with the surface of the twodimensional materials via van der Waals interactions leading to subsequent quenching of the upconversion fluorescence. By contrast, in the presence of a complementary oligonucleotide target and the formation of double-stranded DNA, the upconversion nanoparticles could not interact with $\mathrm{MoS}_{2}$ and $\mathrm{WS}_{2}$, thus retaining their inherent fluorescence properties. Utilizing this sensor we were able to detect target oligonucleotides with high sensitivity and specificity whilst reaching a concentration detection limit as low as $5 \mathrm{~mol} \cdot \mathrm{L}^{-1}$, within minutes.
\end{abstract}

Keywords upconversion nanoparticles, DNA sensor, two-dimensional materials, $\mathrm{MoS}_{2}, \mathrm{WS}_{2}$

\section{Introduction}

There is an ongoing interest towards the development of sensors for the detection of biomolecules [1-4]. Amongst various biomolecules, the detection of DNA and RNA has been of particular interest due to their involvement in a plethora of biological processes including gene regulation and protein production as well as various diseases such as

Received September 5, 2020; accepted October 5, 2020

E-mail: a.kanaras@soton.ac.uk

*These authors contributed equally to this work. cancer [5-7].

Different types of biosensors have been designed capable of detecting DNA or RNA targets utilizing electrochemical, mass-based or optical methods [8]. For example, electrochemical sensors monitor variations in current in a solution containing the target [9]. While these sensors have significant advantages like durability, cheap thin-film applications, small-size dimensions and real-time monitoring, their weakness of being easily affected by temperature changes [10] and their lower sensitivity compared to other biosensors $[11,12]$, limit their widespread availability. Surface acoustic wave sensors are mass-based biosensors that can detect acoustic waves generated by mass loading on their surface [13]. They represent a significant alternative for detection of biomolecules as they are rapid and label-free [14]. However, they present major disadvantages, which include mechanical instability and fragility $[15,16]$. Optical DNA or RNA sensors are based on the interaction of the optical field with nucleic acids [17]. They are broadly used because of their high sensitivity and specificity [18]. The most common types of optical sensors are: label-free systems that rely on plasmon resonance or optical resonance [19], and labelbased systems involving the use of fluorophores, enzymes or nanoparticles [20]. Surface plasmon resonance detection is based on the measurement of binding-induced refractive index changes in a sample region. This type of detection allows for quantitative and kinetic measurement of molecular interactions in real-time [21]. However, it is relatively challenging to develop surface plasmon resonance sensors for small molecules at low concentrations as the molecular weight of the target must be large enough to generate a measurable signal change [22]. Other common optical biosensors that involve the use of organic dyes, rely on the presence of an energy transfer pair in close proximity where the fluorescence of a donor is quenched 
by an acceptor - a process also called Förster resonance energy transfer (FRET) [23]. However, the use of organic dyes presents several limitations, such as the lack of stability due to photo-bleaching and photo-blinking [24]. Moreover, the typical photo-excitation of organic dyes in the UV-visible wavelength range limits their use in complex biological environments due to the presence of undesired background autofluorescence deriving from proteins, cells and other biomolecules [25].

To overcome the aforementioned obstacles, lanthanide doped upconversion nanoparticles (UCNPs) have emerged as reliable alternatives to standard organic fluorophores. The main characteristic of UCNPs is that they can convert near-infrared light into visible light. The use of nearinfrared excitation radiation enables penetration into biological samples more efficiently than visible light due to the optical transparent window of the electromagnetic spectrum in biological tissues [26]. UCNPs show high resistance to photo-bleaching or photo-blinking and they have narrow emissions in the visible area, which renders their fluorescent signal stable and easily detectable in multiplexing biosensors $[27,28]$. For these reasons, the production of highly efficient UCNPs is employed in a wide range of biological applications [29-31].

An effective quencher for UCNPs is graphene oxide. In previous studies, we have shown that UCNPs functionalized with single-stranded DNA can adsorb to the graphene oxide surface via $\pi-\pi$ staking generated interactions between the DNA strand and graphene oxide. Thus the close proximity of the UCNPs to the surface of graphene oxide resulted in the quenching of their fluorescence [32]. In contrast, double-stranded DNA coated UCNPs did not interact with the graphene oxide surface as the nucleobases were efficiently shielded within the negatively charged phosphate backbone of double-stranded DNA [33]. Thus, in the presence of the complementary oligonucleotide sequence the UCNPs did not adsorb to the graphene oxide surface retaining their fluorescence [34]. This methodology was utilized by us to construct sensors for the detection of messenger RNA biomarkers, relevant to Alzheimer's disease and prostate cancer, in complex media such as blood plasma and cell lysate. Furthermore, we demonstrated the fabrication of a portable sensor for the field detection of messenger RNA biomarkers related to crops' nutritional deficiencies [35,36]. Huang et al. also made a sensor for the detection of endonucleases using DNAcoated UCNPs and graphene oxide as a FRET pair. The resulting biosensor exhibited high sensitivity with a limit of detection of $1 \times 10^{-4} \mathrm{U} \cdot \mathrm{mL}^{-1}$ for S1 nuclease [37].

Analogous materials as graphene oxide with special optical and electronic properties have recently been exploited for the fabrication of FRET assays. Twodimensional dichalcogenide materials have emerged as ideal energy transfer acceptors due to their large surface area, ease of synthesis of large single sheets and their increased affinity towards biomolecules. Luminescent two- dimensional materials such as $\mathrm{MoS}_{2}$ and $\mathrm{WS}_{2}$ have also proven to be excellent quenchers in the area of optical biosensors [38]. Single-stranded DNA can adsorb onto the $\mathrm{MoS}_{2}$ and $\mathrm{WS}_{2}$ surface via van der Waals forces rather than $\pi-\pi$ staking interactions [39]. Liu's group studied the adsorption/desorption behavior of single-stranded DNA with these materials by varying the ionic strength, the denaturing agents and the DNA length or sequence. They concluded, that compared to $\mathrm{MoS}_{2}$ and $\mathrm{WS}_{2}$, graphene oxide exhibited the highest affinity for DNA detection whilst the detection limit of these three sensors was quite similar when the same fluorescent DNA probe was used [39]. To greater extent, two-dimensional materials are shown to be very good quenchers in the area of optical aptamer-based sensors. Recently, Kenry and co-workers presented the fluorescence detection of a highly expressed malarial biomarker, Plasmodium lactose dehydrogenase protein, by using single-layer $\mathrm{MoS}_{2}$ nanosheets and singlestranded aptamer probe labeled with the fluorescent dye, fluorescein. This aptamer-nanosheet sensing platform was capable of distinguishing the target Plasmodium lactose dehydrogenase protein in a heterogeneous mixture of proteins [40]. Lv et al. developed a strategy for the detection of microcystin-LR, a representative toxin released by Cyanobacteria in water, using DNA coated UCNPs and $\mathrm{MoS}_{2}$. This aptamer-based sensor was proven to work efficiently even in 'real' samples such as tap and lake water [41]. An aptamer-based sensor was also developed by Yuan et al. Their study focused on the use of $\mathrm{MoS}_{2}$ and UCNPs as a FRET pair for the detection of the tumor marker $\mathrm{VEGF}_{165}$ [42].

In this work, we show how $\mathrm{MoS}_{2}$ and $\mathrm{WS}_{2}$ can be utilized for sensing of a synthetic oligonucleotide target. We demonstrate the detection of a poly-A DNA target in phosphate buffer saline by exploiting the interactions occurring between single-stranded DNA coated UCNPs and $\mathrm{MoS}_{2} / \mathrm{WS}_{2}$ in solution. Scheme 1 depicts the working mechanism of the biosensor. In the presence of $\mathrm{MoS}_{2}$ or $\mathrm{WS}_{2}$, the single-stranded DNA coated UCNPs adsorb onto the surface of the dichalcogenide resulting in fluorescence quenching of the UCNPs. However, when the complementary DNA sequence is present the double-stranded DNA coated UCNPs do not adsorb onto the dichalcogenide surface thus retaining their fluorescent signal. On the other hand, in the presence of a non-complementary sequence, the fluorescence of the UCNPs is quenched and no fluorescent signal is detected, demonstrating the specificity of the sensor.

\section{Experimental}

\subsection{Materials}

All chemical reagents were used as received without further purification and were obtained from commercial 


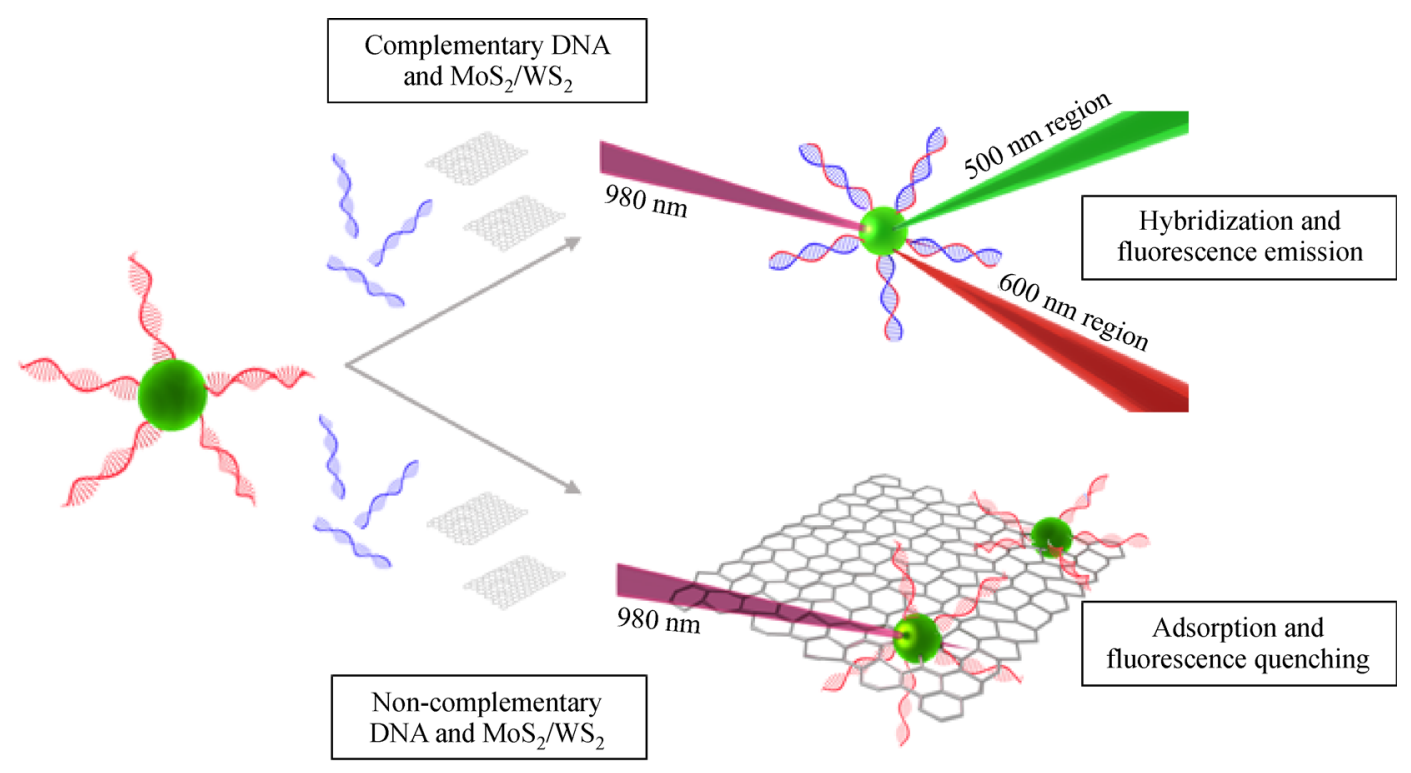

Scheme 1 Schematic illustration presenting the working principle of the DNA sensor. In the absence of a complementary DNA target, $\mathrm{MoS}_{2}$ and $\mathrm{WS}_{2}$ quench the UCNP emitted fluorescence. When hybridized to the complementary DNA target, the double-stranded DNA coated UCNPs do not adsorb to the surface of the dichalcogenides and therefore their fluorescence is retained.

sources. Yttrium(III) chloride hexahydrate (98\%), ytterbium(III) chloride hexahydrate (99.9\%), erbium(III) chloride hexahydrate $(99.9 \%)$, ammonium fluoride $(98 \%)$, methanol $(99.9 \%), n$-hexane $(95 \%)$, poly(acrylic acid) (PAA) (MW $\approx 1.8 \mathrm{kDa}$ ), phosphate buffer saline tablets, 2 ( $N$-morpholino) ethanesulfonic acid, 4-morpholineethanesulfonic acid, sodium borate, sodium chloride, 1-octadecene $(90 \%)$, oleic acid (90\%), $N$-(3-(dimethylamino) propyl)- $N$ '-ethylcarbodiimide hydrochloride (EDC) (99\%) and $N$-hydroxysulfosuccinimide sodium salt (sulfo-NHS) (98\%) were purchased from Merck. Tetrahydrofuran, ethanol and hexane were purchased from Thermo Fisher Scientific in laboratory grade. $\mathrm{MoS}_{2}$ and $\mathrm{WS}_{2}$ (black powders of monolayer sheets dispersed in phosphate buffer saline before use) were purchased from ACS Material. $\mathrm{MoS}_{2}$ monolayers exhibit a diameter between 1-3 $\mu \mathrm{m}$, with a thickness of $\sim 1 \mathrm{~nm}$ and a monolayer ratio $\geqslant 90 \%$ while $\mathrm{WS}_{2}$ monolayers exhibit a diameter between $0.1-4 \mu \mathrm{m}$, a thickness of $\sim 1 \mathrm{~nm}$ and a monolayer ratio of $\geqslant 90 \%$.

\subsection{Methods}

Transmission electron microscopy samples were prepared by depositing a drop of a diluted nanoparticle solution on a 400 mesh formvar coated copper grid and left in air to dry. Nanoparticles were observed on a Hitachi HT7700 Transmission Electron Microscope operating at an accelerating voltage of $100 \mathrm{kV}$. The size distribution of the coreshell UCNPs after annealing treatment was determined to be $27.4 \pm 0.1 \mathrm{~nm}$ by counting over 200 nanoparticles using ImageJ software (National Institutes of Health, USA). The upconversion fluorescence measurements were performed using an aligned setup which consisted of a $300 \mathrm{~mW}$, $980 \mathrm{~nm}$ diode laser (Thorlabs LTD, UK) as an excitation source and a short pass IR-blocking filter (Schott KG3) in order to suppress scattered excitation light and select only the fluorescence emission. The detector was a SpectraSuite Spectrometer (OceanOptics, USA) where the emitted fluorescence was collected perpendicular to the excitation beam using a $35 \mathrm{~mm}$ focal length lens. By illuminating a cuvette filled with the appropriate solvent with the same laser beam, the blank for each measurement was determined. All measurements were performed under $1000 \mathrm{~ms}$ of integration time and 10 scans to average. The fluorescent experiments were repeated three times and the fitted data corresponded to the mean value \pm standard error of the mean.

\subsection{Synthesis of core UCNPs}

The synthesis of core UCNPs was carried out following a published protocol with some modifications [43]. The rare earth salts, $\mathrm{YCl}_{3} \cdot 6 \mathrm{H}_{2} \mathrm{O}(236 \mathrm{mg}, 0.78 \mathrm{mmol})$, $\mathrm{YbCl}_{3} \cdot 6 \mathrm{H}_{2} \mathrm{O}(77.5 \mathrm{mg}, 0.20 \mathrm{mmol})$, and $\mathrm{ErCl}_{3} \cdot 6 \mathrm{H}_{2} \mathrm{O}$ $(7.63 \mathrm{mg}, 0.02 \mathrm{mmol})$ were put in a $100 \mathrm{~mL}$ round-bottom flask together with $6 \mathrm{~mL}$ of oleic acid and $15 \mathrm{~mL}$ of 1 -octadecene. The solution was heated up to $150{ }^{\circ} \mathrm{C}$ under the presence of argon flow and left at this temperature for $1 \mathrm{~h}$ and $30 \mathrm{~min}$. Then, the reaction mixture was cooled down to room temperature. A solution of $\mathrm{NaOH}(100 \mathrm{mg}$, $2.5 \mathrm{mmol})$ and $\mathrm{NH}_{4} \mathrm{~F}(148.16 \mathrm{mg}, 4 \mathrm{mmol})$ dissolved in $10 \mathrm{~mL}$ of dry methanol was injected dropwise to the reaction mixture under vigorous stirring. After $45 \mathrm{~min}$ of stirring at room temperature, the solution was gradually heated up to $100^{\circ} \mathrm{C}$ under argon for an additional $30 \mathrm{~min}$ to 
assist with the evaporation of methanol. Then, the reaction mixture was stirred under vacuum for $30 \mathrm{~min}$ in order to ensure the complete evaporation of the methanol. After, the temperature was increased at $310^{\circ} \mathrm{C}$ under argon and the solution was left under stirring for $1 \mathrm{~h} 20 \mathrm{~min}$ to form the particles. Finally, the particles were left to cool down to room temperature. The solution was rinsed with ethanol $(20 \mathrm{~mL})$ and centrifuged $\left(5000 \mathrm{r} \cdot \mathrm{min}^{-1}, 15 \mathrm{~min}\right)$ three times for particles' purification. Each time UCNPs were redispersed in ethanol $(20 \mathrm{~mL})$. The nanoparticles' pellet was left to dry for several hours, weighted and stored for further experiments.

\subsection{Synthesis of core-shell UCNPs}

The synthesis of core-shell nanocrystals was performed based on a previously published protocol with some modifications [44]. In more detail, $\mathrm{YCl}_{3} \cdot 6 \mathrm{H}_{2} \mathrm{O}$ (151.68 mg, $0.5 \mathrm{mmol})$ was dissolved in a solution of 1-octadecene $(15 \mathrm{~mL})$ and oleic acid $(6 \mathrm{~mL})$ and stirred for $1 \mathrm{~h}$ under argon at $150{ }^{\circ} \mathrm{C}$. The solution was left to cool down to $80^{\circ} \mathrm{C}$ under a steady flow of argon. A solution of core UCNPs $(125 \mathrm{mg})$ dissolved in $\mathrm{CHCl}_{3}(10 \mathrm{~mL})$ was injected dropwise. The solution was gradually heated up to $100{ }^{\circ} \mathrm{C}$ under argon flow for $20 \mathrm{~min}$. Then, the mixture was left to cool down at room temperature under argon. A solution of $\mathrm{NaOH}(50 \mathrm{mg}, 1.25 \mathrm{mmol})$ and $\mathrm{NH}_{4} \mathrm{~F}$ (74.08 $\mathrm{mg}, 2 \mathrm{mmol})$ dissolved in dry methanol $(5 \mathrm{~mL})$ was added dropwise to the reaction mixture and was stirred for other $45 \mathrm{~min}$. Afterwards, the temperature increased gradually up to $130{ }^{\circ} \mathrm{C}$ under argon and the solution was stirred for $30 \mathrm{~min}$. For ensuring the complete evaporation of methanol, it was stirred for other $30 \mathrm{~min}$ at $130^{\circ} \mathrm{C}$ under vacuum. Finally, the temperature was increased at $310{ }^{\circ} \mathrm{C}$ under argon and the mixture was left under stirring for $1 \mathrm{~h}$ $20 \mathrm{~min}$ to form the core-shell particles. After completion of the reaction, the nanoparticles were left to cool down to room temperature. The solution was rinsed with ethanol $(20 \mathrm{~mL})$ and centrifuged $\left(5000 \mathrm{r} \cdot \mathrm{min}^{-1}, 15 \mathrm{~min}\right)$ three times in order to purify the particles. Each time UCNPs were re-dispersed in ethanol $(20 \mathrm{~mL})$. The core-shell UCNPs' pellet was collected and re-dispersed in tetrahydrofuran.

\subsection{Ligand exchange on core-shell UCNPs}

A ligand exchange protocol was followed to coat the nanoparticle surface with PAA in order to bring the UCNPs in water [45]. A solution of PAA $(0.25 \mathrm{~g}, \mathrm{MW} \approx 1.8 \mathrm{kDa})$ dissolved in tetrahydrofuran $(3 \mathrm{~mL})$ was added to the coreshell UCNPs coated with oleic acid and re-dispersed in $7 \mathrm{~mL}$ tetrahydrofuran. The mixture was left stirring for $48 \mathrm{~h}$ at room temperature to allow the ligand exchange to happen. The final solution was centrifuged $\left(5000 \mathrm{r} \cdot \mathrm{min}^{-1}\right.$, $15 \mathrm{~min})$ and washed with ethanol $(20 \mathrm{~mL})$ twice. The particles' pellet was dried and re-suspended in sterile
DNAse/RNAse free Milli-Q water and stored at $4{ }^{\circ} \mathrm{C}$.

\subsection{Synthesis and characterizations of single-stranded DNA PAA coated core-shell UCNPs}

The amino-modified oligonucleotides were covalently attached to the surface of the PAA coated core-shell UCNPs via the carboxylic groups on the PAA ligand using EDC amino-coupling chemistry. A solution of EDC $\left(20 \mu \mathrm{L}, \quad 0.3 \mathrm{~mol} \cdot \mathrm{L}^{-1}\right)$ and sulfo-NHS $(20 \mu \mathrm{L}$, $0.3 \mathrm{~mol} \cdot \mathrm{L}^{-1}$ ) in 4-morpholineethanesulfonic acid buffer (pH 5.5, $0.1 \mathrm{~mol} \cdot \mathrm{L}^{-1}$ ) was added to PAA coated core-shell UCNPs $\left(0.5 \mathrm{mg} \cdot \mathrm{mL}^{-1}\right)$ suspended in borate buffer $(\mathrm{pH} 8.5$, $\left.0.01 \mathrm{~mol} \cdot \mathrm{L}^{-1}\right)$. The mixture was sonicated $(10 \mathrm{~min})$ thus the desired amino-terminated oligonucleotide sequence was added (poly-T, $22 \mu \mathrm{L}, 236 \mu \mathrm{mol} \cdot \mathrm{L}^{-1}$ ). The reaction was stirred overnight, and the particles were purified by centrifugation $\left(16400 \mathrm{r} \cdot \mathrm{min}^{-1}, 4{ }^{\circ} \mathrm{C}, 10 \mathrm{~min}\right)$ three times. The functionalized with single-stranded DNA core-shell UCNPs were re-suspended in phosphate buffer saline and stored at $4{ }^{\circ} \mathrm{C}$.

\subsection{Sensor calibration}

In order to accurately calibrate the sensor, increasing concentrations of two-dimensional materials (0.1$1.3 \mathrm{mg} \cdot \mathrm{mL}^{-1}$ ) were added to a solution containing a fixed concentration of functionalized UCNPs $\left(0.5 \mathrm{mg} \cdot \mathrm{mL}^{-1}\right)$ dispersed in phosphate buffer saline. The corresponding fluorescence spectra of the DNA coated UCNPs were monitored in order to determine the concentration of the two-dimensional materials that would result in optimum fluorescence quenching.

\subsection{Targeted DNA detection using DNA coated UCNPs}

In order to prevent the interaction between the singlestranded DNA coated UCNPs and the two-dimensional materials, the single-stranded DNA was hybridized with its complementary sequence before incubating with the twodimensional material. To this purpose, $0.5 \mathrm{mg} \cdot \mathrm{mL}^{-1}$ of single-stranded DNA coated UCNPs were incubated in phosphate buffer saline with various concentrations of the complementary DNA strand (ranging from $5 \mathrm{fmol} \cdot \mathrm{L}^{-1}$ to $50 \mathrm{nmol} \cdot \mathrm{L}^{-1}$ ) overnight while shaking. After this, a solution of $\mathrm{MoS}_{2}$ or $\mathrm{WS}_{2}$ dispersed in phosphate buffer saline was added and left incubating for $10 \mathrm{~min}$ prior to performing the fluorescence measurements.

\section{Results and discussion}

3.1 Synthesis and characterization of oligonucleotide functionalized UCNPs

In order to investigate the interactions occurring between 
single-stranded DNA coated UCNPs and $\mathrm{MoS}_{2} / \mathrm{WS}_{2}$, we firstly synthesized hexagonal phase $\mathrm{NaYF}_{4}: \mathrm{Yb}^{3+}(18 \%)$; $\mathrm{Er}^{3+}(2 \%) @ \mathrm{NaYF}_{4}$ core-shell NPs based on a modified solvothermal method [46]. Our synthesis yielded highly monodisperse hexagonal shaped core-shell UCNPs with an average nanocrystal size of $27.4 \pm 0.1 \mathrm{~nm}$ (see Fig. S1, cf. Electronic Supplementary Material, ESM). X-ray diffraction measurements confirmed that the hexagonal phase of the UCNPs was retained after core-shell formation (see Fig. S2, cf. ESM). The presence of the $\mathrm{NaYF}_{4}$ shell accounted for a decrease of defects on the UCNPs crystal surface thus improving their fluorescent emission in water where the upconversion processes can be strongly affected by vibrational scattering of water molecules adsorbed onto the crystal surface $[47,48]$. Following our previously established protocols, a ligand exchange procedure was further performed where the original oleic acid ligands on the UCNP surface were replaced by PAA to enable nanoparticle solubility in water and further facilitate their functionalization with amino-modified single-stranded DNA sequences [35,36]. An EDC coupling reaction was utilized in order to attach the amino-modified synthetic oligonucleotides to the carboxylic group of the PAA ligands on the UCNPs surface. The successful coupling was firstly confirmed by zeta potential measurements where a decrease in the net charge was observed (see Fig. S4, cf. ESM) and Fourier-transform infrared spectroscopic analysis where the characteristic peak of the carboxyl group of the PAA disappeared (see Fig. S5, cf. ESM).

\subsection{Quenching of UCNPs' fluorescence by $\mathrm{MoS}_{2}$ and $\mathrm{WS}_{2}$}

Following successful synthesis and characterization of single-stranded DNA coated UCNPs we evaluated the ability of $\mathrm{MoS}_{2}$ and $\mathrm{WS}_{2}$ (see Fig. S6 (cf. ESM), for characterization of $\mathrm{MoS}_{2}$ and $\mathrm{WS}_{2}$ ) to quench the emission of the functionalized NPs. Figure 1 shows the recorded

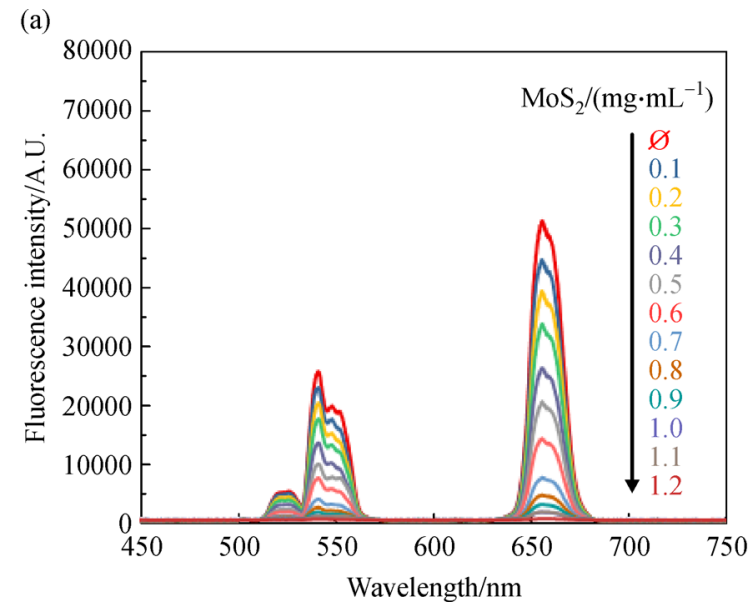

fluorescence spectra of single-stranded DNA coated UCNPs $\left(0.5 \mathrm{mg} \cdot \mathrm{mL}^{-1}\right)$ in the presence of various concentrations of $\mathrm{MoS}_{2}$ and $\mathrm{WS}_{2}$. Upon increasing concentrations of two-dimensional materials, whilst maintaining the same concentration of single-stranded DNA coated UCNPs $\left(0.5 \mathrm{mg} \cdot \mathrm{mL}^{-1}\right)$, a steady decrease in the fluorescence intensity of the UCNPs was observed. This is a strong indication that the interactions between the twodimensional materials and single-stranded DNA coated UCNPs were within the distance required for a nonradiative energy transfer, which resulted in fluorescence quenching [49].

To further investigate the nature of the interactions occurring between the single-stranded DNA coated UCNPs and the two-dimensional dichalcogenides we correlated the intensity at lambda max for each UCNP emission peak observed in the fluorescence spectra with the quenching ability of $\mathrm{MoS}_{2}$ and $\mathrm{WS}_{2}$. Figure 2 shows the analysis of fluorescence quenching of single-stranded DNA coated UCNPs at wavelengths of 540 and $655 \mathrm{~nm}$ as a function of $\mathrm{MoS}_{2}$ and $\mathrm{WS}_{2}$ concentration. Indeed, a quenching ability of more than $94 \%$ was observed upon addition of $1.2 \mathrm{mg} \cdot \mathrm{mL}^{-1}$ of $\mathrm{MoS}_{2}$ and $1.3 \mathrm{mg} \cdot \mathrm{mL}^{-1}$ of $\mathrm{WS}_{2}$ respectively. This degree of quenching correlates well with the quenching effect previously observed for graphene oxide against the UCNPs' emitted fluorescence as a result of the FRET process occurring between the donor (UCNPs) and the acceptor (two-dimensional material) $[34,49]$. In this study, the UCNPs fluorescence quenching followed the same trend, which indicates that this quenching is due to a FRET process.

\subsection{Oligonucleotide target detection}

In order to fully investigate the ability of single-stranded DNA coated UCNPs to induce an interaction with the chosen two-dimensional materials we incubated $\mathrm{MoS}_{2}$ and $\mathrm{WS}_{2}$, at concentrations previously determined to induce

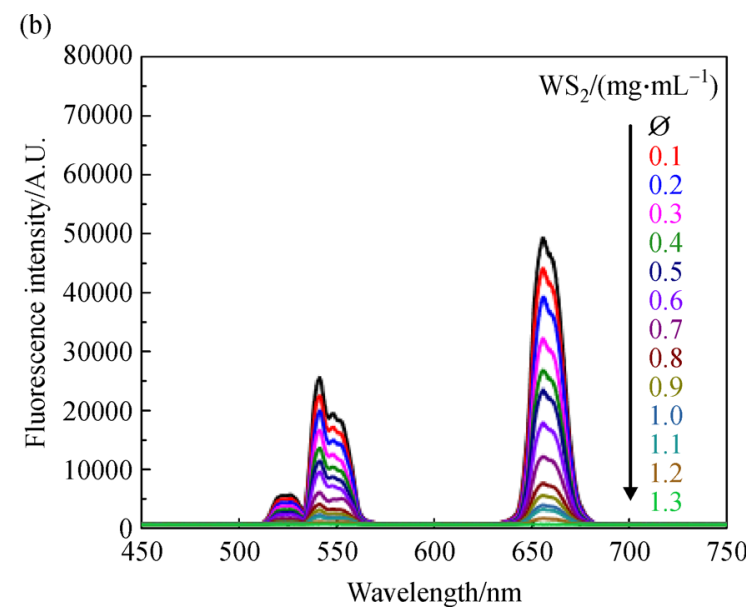

Fig. 1 Representative fluorescence emission spectra from single-stranded DNA coated UCNPs $\left(0.5 \mathrm{mg} \cdot \mathrm{mL}^{-1}\right)$ in the presence of increasing concentrations of (a) $\mathrm{MoS}_{2}$ or (b) $\mathrm{WS}_{2}$. 

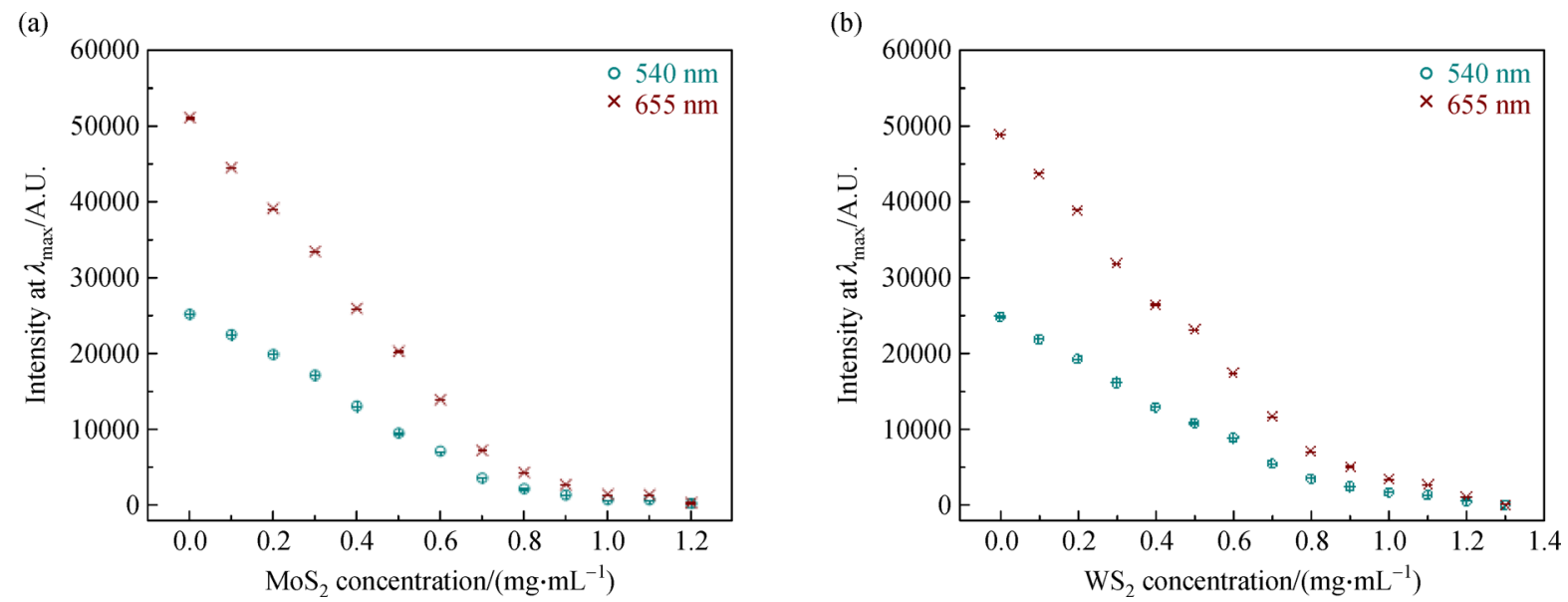

Fig. 2 Correlated fluorescence emission spectra from single-stranded DNA coated UCNPs $\left(0.5 \mathrm{mg} \cdot \mathrm{mL}^{-1}\right)$ showing the decreasing fluorescence emission of the $\lambda_{\max }$ of the two typical peaks of UCNPs $(655 \mathrm{~nm}$, red points; $540 \mathrm{~nm}$, cyan points $)$ in the presence of increasing concentration of (a) $\mathrm{MoS}_{2}$ or (b) $\mathrm{WS}_{2}$ as indicated in the graph.

the most effective quenching with functionalized UCNPs. Figure 2 shows that the distinct fluorescence emission of UCNPs was significantly quenched when coated with a monolayer of single-stranded DNA indicating that the main driving forces rely on van der Waals interactions between the single-stranded DNA and the two-dimensional surface as also reported by others $[39,49]$. To further investigate the presence of such interactions, singlestranded DNA coated UCNPs were hybridized to their complementary sequences (see Table S1 (cf. ESM) for oligonucleotide sequences) and then $\mathrm{MoS}_{2}$ or $\mathrm{WS}_{2}$ were added. Figure 3 shows results obtained upon hybridization with an increasing concentration of complementary DNA target for $30 \mathrm{~min}$. As the concentration of the target was increased from $5 \mathrm{fmol} \cdot \mathrm{L}^{-1}$ to $50 \mathrm{nmol} \cdot \mathrm{L}^{-1}$, a decrease in the quenching efficiency of $\mathrm{MoS}_{2}$ (Fig. 3(a)) and $\mathrm{WS}_{2}$ (Fig. 3(b)) over both characteristic peaks was observed. This is due to the conformational change taking place upon

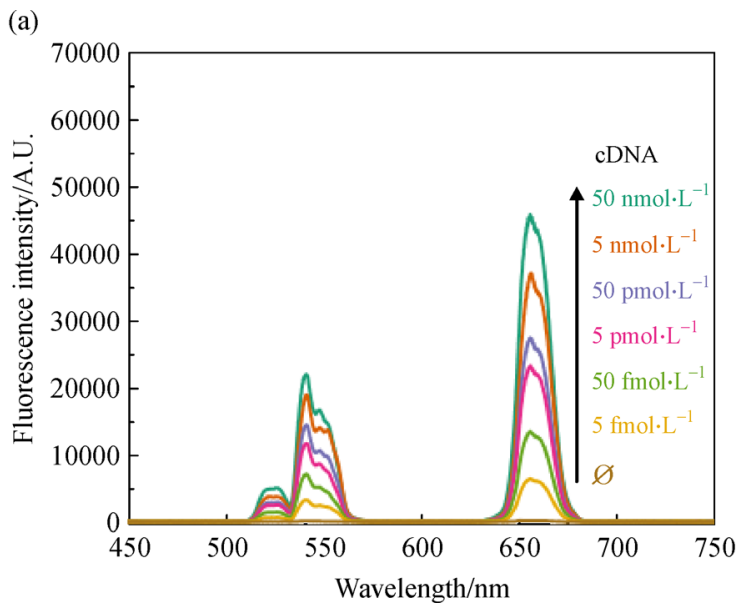

DNA duplex formation, which prevented adsorption of the double-stranded DNA coated UCNPs onto the $\mathrm{MoS}_{2}$ or $\mathrm{WS}_{2}$ surface thus retaining their fluorescence properties.

Figure 4 shows the maximum intensity recorded for each peak at wavelengths of 540 and $655 \mathrm{~nm}$ as a function of the target concentration. By plotting a semi-log graph, a trend was observed where a pronounced effect in fluorescence recovery was observed at a concentration of 50 and $5 \mathrm{nmol} \cdot \mathrm{L}^{-1}$ for $\mathrm{MoS}_{2}$ (Fig. 4(a)) and $\mathrm{WS}_{2}$ (Fig. 4(b)) respectively. For lower target concentrations, fluorescence recovery was less efficient due to potential lower number of hybridization events occurring. Thus quenching by $\mathrm{MoS}_{2}$ and $\mathrm{WS}_{2}$ due to adsorption of single-stranded DNA coated UCNPs onto the surface was still observed at such complementary DNA concentrations demonstrating that fluorescence intensity is dependent on target detection.

The specificity of this system was further confirmed by performing a control experiment where single-stranded

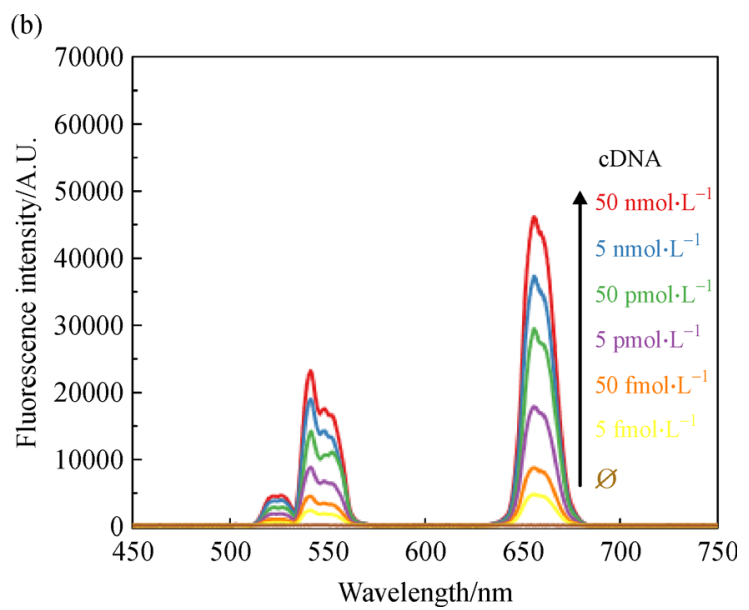

Fig. 3 Representative fluorescence spectra of single-stranded DNA coated UNCPs $\left(0.5 \mathrm{mg} \cdot \mathrm{mL}^{-1}\right)$ in the presence of increasing concentrations of complementary DNA targets for (a) $\mathrm{MoS}_{2}$ and (b) $\mathrm{WS}_{2}$. 
(a)

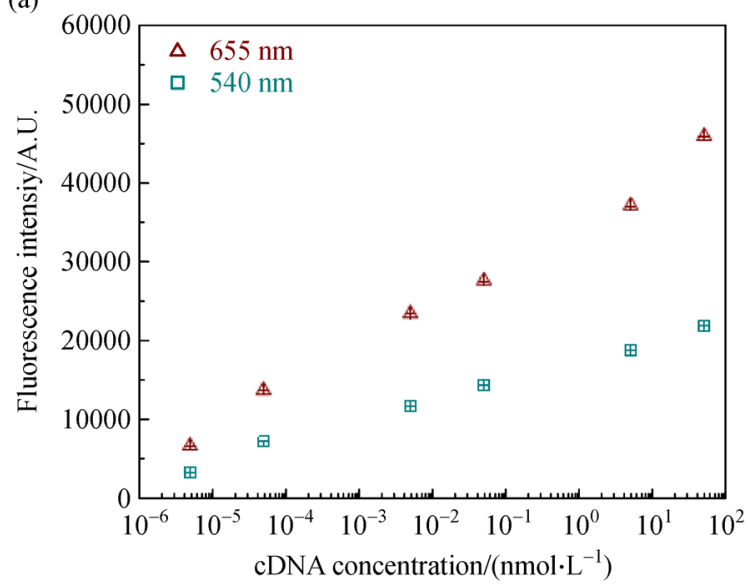

(b)

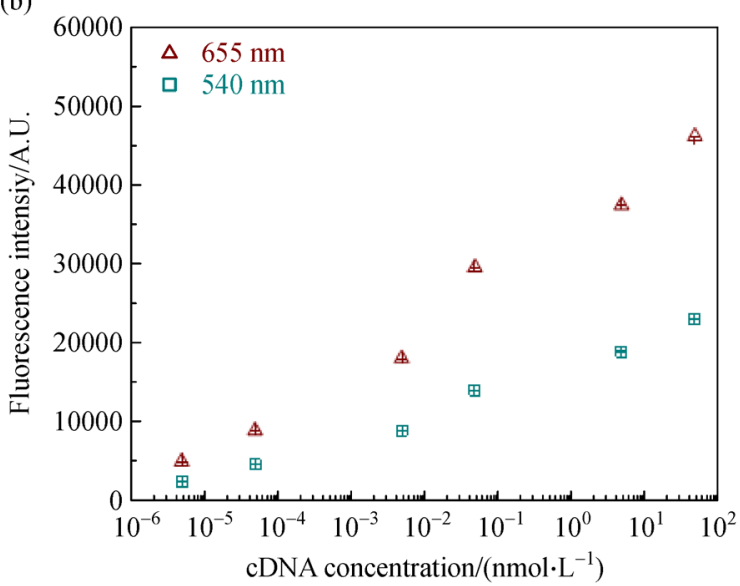

Fig. 4 Graphs of the maximum nanoparticle fluorescence intensity bands measured at 540 and $655 \mathrm{~nm}$ for (a) $\mathrm{MoS}_{2}$ and (b) WS $\mathrm{W}_{2}$ as a function of complementary DNA concentration.

DNA coated UCNPs $\left(0.5 \mathrm{mg} \cdot \mathrm{mL}^{-1}\right)$ were incubated with a non-complementary target sequence prior to addition of $\mathrm{MoS}_{2}$ and $\mathrm{WS}_{2}$. Figure 5 shows the fluorescence emission spectra recorded following incubation with DNA concentrations ranging from 5 to $1000 \mathrm{nmol} \cdot \mathrm{L}^{-1}$. In both cases no fluorescence was observed (Fig. 5) regardless of the concentration of the non-complementary DNA target initially added. This indicated the predominant existence of single-stranded DNA on the UCNP surface, which permitted their adsorption onto the surface of $\mathrm{MoS}_{2}$ or $\mathrm{WS}_{2}$ respectively, thus rendering their fluorescence quenched.

\section{Conclusions}

In summary, we showed the development and use of an optical DNA sensor made from single-stranded DNA coated UCNPs and two-dimensional dichalcogenides

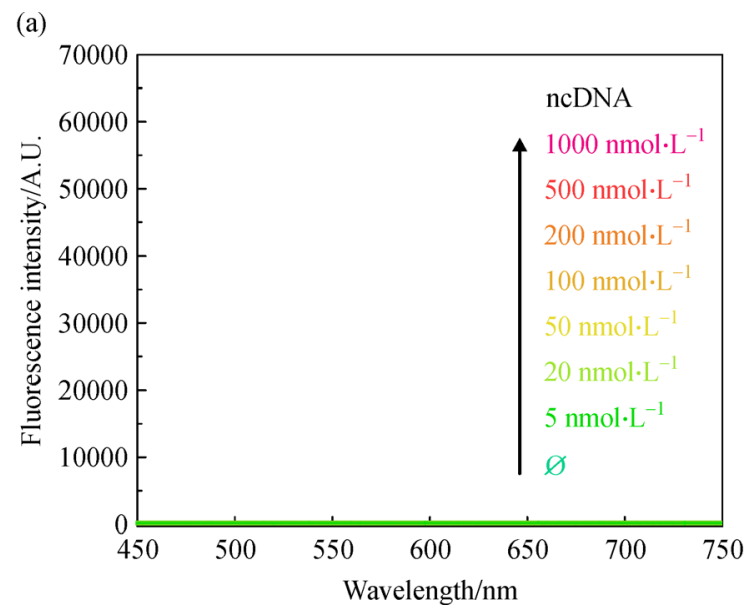

$\left(\mathrm{MoS}_{2}\right.$ and $\left.\mathrm{WS}_{2}\right)$. The well-developed concept of a sensor, which combines the emissive properties of UCNPs and the quenching ability of graphene oxide, has been herein implemented by considering alternative two-dimensional materials. The working principle of the sensor is based on the property of dichalcogenides to adsorb single-stranded DNA to their surface via van der Waals interactions. In the absence of a target DNA, single-stranded DNA coated UCNPs were adsorbed onto the surface of $\mathrm{MoS}_{2}$ or $\mathrm{WS}_{2}$ and their fluorescence was quenched. In the presence of a complementary target DNA hybridized to the oligonucleotides on the surface of the UCNPs, the particles could no longer adsorb to the surface of the dichalcogenides and their fluorescence was retained. Utilizing this sensor, we were able to detect target DNAs within few minutes at the $5 \mathrm{fmol} \cdot \mathrm{L}^{-1}$ range. Our results pave the way towards the development of oligonucleotide sensors for related biomedical applications. Future research could also involve other dichalcogenide such as $\mathrm{TaS}_{2}$ and $\mathrm{TiS}_{2}$, which have

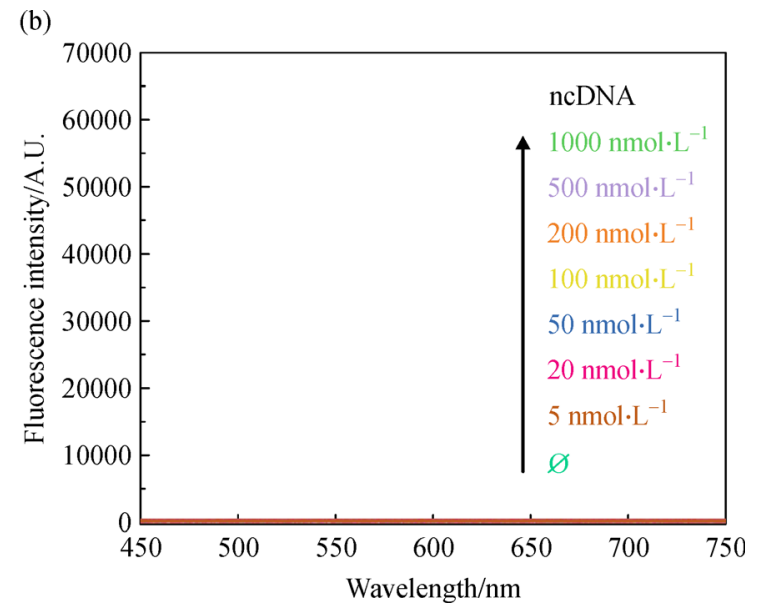

Fig. 5 Fluorescence spectra of single-stranded DNA coated UCNPs $\left(0.5 \mathrm{mg} \cdot \mathrm{mL}^{-1}\right)$ in the presence of various concentrations of the noncomplementary target for (a) $1.2 \mathrm{mg} \cdot \mathrm{mL}^{-1} \mathrm{MoS}_{2}$ and (b) $1.3 \mathrm{mg} \cdot \mathrm{mL}^{-1} \mathrm{WS}_{2}$. 
already been found to serve as suitable energy transfer acceptors upon their interaction with dye-modified oligonucleotides [50].

Acknowledgements Antonios G. Kanaras, Otto L. Muskens and Davide Giust would like to acknowledge funding from BBSRC (Grant No. BB/ N021150/1). Konstantina Alexaki would like to thank the University of Southampton for a Mayflower doctor of philosophy studentship.

Electronic Supplementary Material Supplementary material is available in the online version of this article at https://oi.org/10.1007/s11705-0202023-9. Additional Raw data of this work is available at https://doi.org/ $10.5258 /$ SOTON/D1553.

Open Access This article is licensed under a Creative Commons Attribution 4.0 International License, which permits use, sharing, adaptation, distribution and reproduction in any medium or format, as long as you give appropriate credit to the original author(s) and the source, provide a link to the Creative Commons licence, and indicate if changes were made. The images or other third party material in this article are included in the article's Creative Commons licence, unless indicated otherwise in a credit line to the material. If material is not included in the article's Creative Commons licence and your intended use is not permitted by statutory regulation or exceeds the permitted use, you will need to obtain permission directly from the copyright holder. To view a copy of this licence, visit http://creativecommons.org/licenses/by/4.0/.

\section{References}

1. Wang J. DNA biosensors based on peptide nucleic acid (PNA) recognition layers. A review. Biosensors \& Bioelectronics, 1998, 13 (7-8): 757-762

2. Leatherbarrow R J, Edwards P R. Analysis of molecular recognition using optical biosensors. Current Opinion in Chemical Biology, 1999, 3(5): 544-547

3. Akyilmaz E, Yorganci E, Asav E. Do copper ions activate tyrosinase enzyme? A biosensor model for the solution. Bioelectrochemistry, 2010, 78(2): 155-160

4. Soraya G V, Chan J X, Nguyen T C, Huynh D H, Abeyrathne C D, Chana G, Todaro M, Skafidas E, Kwan P. An interdigitated electrode biosensor platform for rapid HLA-B*15:02 genotyping for prevention of drug hypersensitivity. Biosensors \& Bioelectronics, 2018, 111: 174-183

5. Contag $\mathrm{C} \mathrm{H}$, Bachmann $\mathrm{M} \mathrm{H}$. Advances in in vivo bioluminescence imaging of gene expression. Annual Review of Biomedical Engineering, 2002, 4(1): 235-260

6. Heuer Jungemann A, El Sagheer A H, Lackie P M, Brown T, Kanaras A G. Selective killing of cells triggered by their mRNA signature in the presence of smart nanoparticles. Nanoscale, 2016, 8 (38): 16857-16861

7. Halo T L, McMahon K M, Angeloni N L, Xu Y, Wang W, Chinen A B, Malin D, Strekalova E, Cryns V L, Cheng C, et al. NanoFlares for the detection, isolation, and culture of live tumor cells from human blood. Proceeding of the National Academy of Sciences of the United States of America, 2014, 111(48): 17104-17109

8. Mobed A, Hasanzadeh M, Ahmadalipour A, Fakhari A. Recent advances in the biosensing of neurotransmitters: material and method overviews towards the biomedical analysis of psychiatric disorders. Analytical Methods, 2020, 12(4): 557-575
9. Blair E O, Corrigan D K. A review of microfabricated electrochemical biosensors for DNA detection. Biosensors \& Bioelectronics, 2019, 134: 57-67

10. Mehrvar M, Abdi M. Recent developments, characteristics, and potential applications of electrochemical biosensors. Analytical Sciences, 2004, 20(8): 1113-1126

11. Matharu Z, Daggumati P, Wang L, Dorofeeva T S, Li Z D, Seker E. Nanoporous-gold-based electrode morphology libraries for investigating structure-property relationships in nucleic acid based electrochemical biosensors. ACS Applied Materials \& Interfaces, 2017, 9(15): 12959-12966

12. Garcia T, Revenga Parraa M, Anorga L, Arana S, Pariente F, Lorenzo E. Disposable DNA biosensor based on thin-film gold electrodes for selective Salmonella detection. Sensors and Actuators. B, Chemical, 2012, 161(1): 1030-1037

13. Lange K, Rapp B E, Rapp M. Surface acoustic wave biosensors: a review. Analytical and Bioanalytical Chemistry, 2008, 391(5): 1509-1519

14. Ten S T, Hashim U, Gopinath S C B, Liu W W, Foo K L, Sam S T, Rahman S F A, Voon C H, Nordin A N. Highly sensitive Escherichia coli shear horizontal surface acoustic wave biosensor with silicon dioxide nanostructures. Biosensors \& Bioelectronics, 2017, 93: 146-154

15. Zhang Y L, Yang F, Sun Z Y, Li Y T, Zhang G J. A surface acoustic wave biosensor synergizing DNA-mediated in situ silver nanoparticle growth for a highly specific and signal-amplified nucleic acid assay. Analyst (London), 2017, 142(18): 3468-3476

16. Afzal A, Mujahid A, Schirhagl R, Bajwa S Z, Latif U, Feroz S. Gravimetric viral diagnostics: QCM based biosensors for early detection of viruses. Chemosensors, 2017, 5(1): 7

17. Damborsky P, Svitel J, Katrlik J. Optical biosensors. Essays in Biochemistry, 2016, 60(1): 91-100

18. Dey D, Goswami T. Optical biosensors: a revolution towards quantum nanoscale electronics device fabrication. Journal of Biomedicine \& Biotechnology, 2011, 10(5204): 348218

19. Shin Y, Perera A P, Park M K. Label-free DNA sensor for detection of bladder cancer biomarkers in urine. Sensors and Actuators. B, Chemical, 2013, 178: 200-206

20. Petty J T, Story S P, Hsiang J C, Dickson R M. DNA-templated molecular silver fluorophores. Journal of Physical Chemistry Letters, 2013, 4(7): 1148-1155

21. Nguyen H H, Park J, Kang S, Kim M. Surface plasmon resonance: a versatile technique for biosensor applications. Sensors (Basel), 2015, 15(5): 10481-10510

22. Patil P O, Pandey G R, Patil A G, Borse V B, Deshmukh P K, Patil D R, Tade R S, Nangare S N, Khan Z G, Patil A M, et al. Graphenebased nanocomposites for sensitivity enhancement of surface plasmon resonance sensor for biological and chemical sensing: a review. Biosensors \& Bioelectronics, 2019, 139: 111324

23. Shi J Y, Tian F, Lyu J, Yang M. Nanoparticle based fluorescence resonance energy transfer (FRET) for biosensing applications. Journal of Materials Chemistry. B, Materials for Biology and Medicine, 2015, 3(35): 6989-7005

24. Schuster J, Brabandt J, Von Borczyskowski C. Discrimination of photoblinking and photobleaching on the single molecule level. Journal of Luminescence, 2007, 127(1): 224-229 
25. Frangioni J V. In vivo near-infrared fluorescence imaging. Current Opinion in Chemical Biology, 2003, 7(5): 626-634

26. Smith A M, Mancini M C, Nie S M. Bioimaging second window for in vivo imaging. Nature Nanotechnology, 2009, 4(11): 710-711

27. Binnemans K. Lanthanide-based luminescent hybrid materials. Chemical Reviews, 2009, 109(9): 4283-4374

28. Wang X, Valiev R R, Ohulchanskyy T Y, Agren H, Yang C, Chen G. Dye-sensitized lanthanide-doped upconversion nanoparticles. Chemical Society Reviews, 2017, 46(14): 4150-4167

29. Wang Y F, Liu G Y, Sun L D, Xiao J W, Zhou J C, Yan C H. Nd ${ }^{3+}$ sensitized upconversion nanophosphors: efficient in vivo bioimaging probes with minimized heating effect. ACS Nano, 2013, 7(8): 7200-7206

30. Liu J, Liu Y, Bu W, Bu J, Sun Y, Du J, Shi J. Ultrasensitive nanosensors based on upconversion nanoparticles for selective hypoxia imaging in vivo upon near-infrared excitation. Journal of the American Chemical Society, 2014, 136(27): 9701-9709

31. Chen Z, Chen H, Hu H, Yu M, Li F, Zhang Q, Zhou Z, Yi T, Huang C. Versatile synthesis strategy for carboxylic acid-functionalized upconverting nanophosphors as biological labels. Journal of the American Chemical Society, 2008, 130(10): 3023-3029

32. Huang Y X, Shi Y M, Yang H Y, Ai Y. A novel single-layered $\mathrm{MoS}_{2}$ nanosheet based microfluidic biosensor for ultrasensitive detection of DNA. Nanoscale, 2015, 7(6): 2245-2249

33. Wu M, Kempaiah R, Huang P J J, Maheshwari V, Liu J W. Adsorption and desorption of DNA on graphene oxide studied by fluorescently labeled oligonucleotides. Langmuir, 2011, 27(6): 2731-2738

34. Alonso Cristobal P, Vilela P, El Sagheer A, Lopez Cabarcos E, Brown T, Muskens O L, Rubio Retama J, Kanaras A G. Highly sensitive DNA sensor based on upconversion nanoparticles and graphene oxide. ACS Applied Materials \& Interfaces, 2015, 7(23): 12422-12429

35. Vilela P, El Sagheer A, Millar T M, Brown T, Muskens O L, Kanaras A G. Graphene oxide-upconversion nanoparticle based optical sensors for targeted detection of mRNA biomarkers present in Alzheimer's disease and prostate cancer. ACS Sensors, 2017, 2 (1): $52-56$

36. Giust D, Lucio M I, El Sagheer A H, Brown T, Williams L E, Muskens O L, Kanaras A G. Graphene oxide-upconversion nanoparticle based portable sensors for assessing nutritional deficiencies in crops. ACS Nano, 2018, 12(6): 6273-6279

37. Huang L J, Tian X, Yi J T, Yu R Q, Chu X. A turn-on upconversion fluorescence resonance energy transfer biosensor for ultrasensitive endonuclease detection. Analytical Methods, 2015, 7(18): 74747479

38. Wang F F, Qu X T, Liu D X, Ding C P, Zhang C L, Xian Y Z. Upconversion nanoparticles- $\mathrm{MoS}_{2}$ nanoassembly as a fluorescent turn-on probe for bioimaging of reactive oxygen species in living cells and zebrafish. Sensors and Actuators. B, Chemical, 2018, 274 :
$180-187$

39. Lu C, Liu Y B, Ying Y B, Liu J W. Comparison of $\mathrm{MoS}_{2}, \mathrm{WS}_{2}$, and graphene oxide for DNA adsorption and sensing. Langmuir, 2017, 33(2): 630-637

40. Kenry G A, Zhang X, Zhang H, Lim C T. Highly sensitive and selective aptamer-based fluorescence detection of a malarial biomarker using single-layer $\mathrm{MoS}_{2}$ nanosheets. ACS Sensors, 2016, 1(11): 1315-1321

41. Lv J J, Zhao S, Wu S J, Wang Z P. Upconversion nanoparticles grafted molybdenum disulfide nanosheets platform for microcystinLR sensing. Biosensors \& Bioelectronics, 2017, 90: 203-209

42. Yuan Y, Yu H, Yin Y. A highly sensitive aptasensor for vascular endothelial growth factor based on fluorescence resonance energy transfer from upconversion nanoparticles to $\mathrm{MoS}_{2}$ nanosheets. Analytical Methods: Advancing Methods and Applications, 2020, 12(36): 4466-4472

43. Li Z Q, Zhang Y. An efficient and user-friendly method for the synthesis of hexagonal-phase $\mathrm{NaYF}_{4}: \mathrm{Yb}, \mathrm{Er} / \mathrm{Tm}$ nanocrystals with controllable shape and upconversion fluorescence. Nanotechnology, 2008, 19(34): 345606

44. Wang F, Deng R R, Liu X G. Preparation of core-shell $\mathrm{NaGdF}_{4}$ nanoparticles doped with luminescent lanthanide ions to be used as upconversion-based probes. Nature Protocols, 2014, 9(7): 16341644

45. Lin W, Fritz K, Guerin G, Bardajee G R, Hinds S, Sukhovatkin V, Sargent E H, Scholes G D, Winnik M A. Highly luminescent lead sulfide nanocrystals in organic solvents and water through ligand exchange with poly(acrylic acid). Langmuir, 2008, 24(15): 82158219

46. Wang M, Abbineni G, Clevenger A, Mao C B, Xu S K. Upconversion nanoparticles: synthesis, surface modification and biological applications. Nanomedicine; Nanotechnology, Biology, and Medicine, 2011, 7(6): 710-729

47. Huang X Y, Lin J. Active-core/active-shell nanostructured design: an effective strategy to enhance $\mathrm{Nd}^{3+} / \mathrm{Yb}^{3+}$ cascade sensitized upconversion luminescence in lanthanide-doped nanoparticles. Journal of Materials Chemistry. C, Materials for Optical and Electronic Devices, 2015, 3(29): 7652-7657

48. Nie Z Y, Ke X X, Li D N, Zhao Y L, Zhu L L, Qiao R, Zhang X L. $\mathrm{NaYF}_{4}: \mathrm{Yb}, \mathrm{Er}, \mathrm{Nd} @ \mathrm{NaYF}_{4}: \mathrm{Nd}$ upconversion nanocrystals capped with $\mathrm{Mn}: \mathrm{TiO}_{2}$ for $808 \mathrm{~nm}$ NIR-triggered photocatalytic applications. Journal of Physical Chemistry C, 2019, 123(37): 2295922970

49. Neema P M, Tomy A M, Cyriac J. Chemical sensor platforms based on fluorescence resonance energy transfer (FRET) and 2D materials. Trac-Trends in Analytical Chemistry, 2020, 124: 115797

50. Hu Y L, Huang Y, Tan C L, Zhang X, Lu Q P, Sindoro M, Huang X, Huang W, Wang L H, Zhang H. Two-dimensional transition metal dichalcogenide nanomaterials for biosensing applications. Materials Chemistry Frontiers, 2017, 1(1): 24-36 